\title{
ВMJ Global Health Still a leap of faith: microfinance initiatives for reduction of violence against women and children in low- income and middle-income countries
}

\author{
Amber Peterman, ${ }^{1,2}$ Tia M Palermo, ${ }^{1}$ Giulia Ferrari ${ }^{3,4}$
}

To cite: Peterman A, Palermo TM, Ferrari G. Still a leap of faith: microfinance initiatives for reduction of violence against women and children in lowincome and middle-income countries. BMJ Glob Health 2018:3:e001143. doi:10.1136/ bmjgh-2018-001143

Handling editor Seye Abimbola

Received 28 August 2018 Revised 16 0ctober 2018 Accepted 23 October 2018

A Check for updates

C Author(s) (or their employer(s)) 2018. Re-use permitted under CC BY-NC. No commercial re-use. See rights and permissions. Published by BMJ.

${ }^{1}$ Social and Economic Policy Unit, UNICEF Office of Research-Innocenti, Florence, Italy ${ }^{2}$ Department of Public Policy, University of North Carolina, Chapel Hill, North Carolina, USA ${ }^{3}$ Department of Global Health and Development, Faculty of Public Health and Policy, London School of Hygiene and Tropical Medicine, London, UK ${ }^{4}$ Centre for Academic Primary Care, Bristol Medical School, University of Bristol, Bristol, UK

Correspondence to Dr Amber Peterman; amberpeterman@gmail.com
Economic strengthening interventions are proposed to reduce interpersonal violence, including intimate partner violence (IPV) and violence against children (VAC) in low-income and middle-income countries (LMICs). ${ }^{1-5}$ This proposition is intuitive, as economic or poverty status and violence are typically correlated. ${ }^{6}{ }^{7}$ However, economic interventions are not uniform. Programmes such as social safety nets (eg, cash or in-kind transfers); livelihood, employment or entrepreneurship programmes; microcredit and savings or broader economic policy instruments (eg, tax credits or fiscal subsidies) induce diverse behavioural changes leading to a variety of outcomes by nature of their different designs and target populations. Further, impacts on violence and its predictors may vary by context according to the levels of generalised poverty and cultural or gender norms. Given the global scale of violence, it is imperative to identify effective prevention strategies through rigorous testing in multiple contexts building a reliable evidence base, before recommending scale-up for violence reduction.

One type of economic intervention, microfinance institutions (MFIs), including microcredit, micro-savings and individual or group village savings and loan associations (VSLAs), have been highlighted as promising interventions for reducing VAC/IPV by INSPIRE, a multinational partnership launched in July $2016 .^{5}$ The INSPIRE package is led by the WHO in collaboration with the Centers for Disease Control and Prevention (CDC), End Violence Against Children: The Global Partnership, the Pan American Health Organization (PAHO), the President's Emergency Plan for AIDS Relief (PEPFAR), Together for Girls, UNICEF, United Nations Office on Drugs and Crime (UNODC), United
Summary box

- Economic strengthening interventions, including microfinance initiatives have been proposed as promising strategies to reduce interpersonal violence in low-income and middle-income settings.

- Despite these recommendations, there is little rigorous empirical evidence that microfinance alone or synergistically with gender norms or equity training can reduce violence against children or intimate partner violence.

- We call for further investments in evidence generation around economic strengthening before scaling-up potentially ineffective interventions.

States Agency for International Development (USAID) and the World Bank. Each letter of the word 'INSPIRE' stands for one of the seven evidence-based strategies including: (1) Implementation and enforcement of laws, (2) Norms and values, (3) Safe environments, (4) Parent and caregiver support, (5) Income and economic strengthening, (6) Response and support services and (7) Education and life skills. INSPIRE promotes two types of bundled MFI programmes ('MFI-plus') among its income and economic strengthening strategies for reducing VAC: group savings and loans combined with gender-equity training and microfinance combined with gendernorms training. ${ }^{5}$ Thus, the INSPIRE strategy implies that (1) mechanisms for impact are driven by the economic or poverty channel (rather than norms or values channel, or by MFI simply being a platform for reaching women in organised groups) and (2) MFIs reduce poverty (and subsequently VAC/IPV), thereby recommending countries should 'adapt and adopt' similar strategies.

Nevertheless, there exists little rigorous evidence showing that MFIs alone or through synergistic effects with other interventions 
reduce VAC in LMICs, or unpacking the mechanisms through which these reductions may occur. In fact, to our knowledge, only three studies evaluate effects of bundled MFI programmes on VAC within samples of adolescent girls in East and Southern Africa. The 'plus' components examined ranged from behaviour change communication, and girls clubs, to livelihood training and other economic transfers. Two experimental studies indicate promising results, finding decreases in experience of 'unwilling sex' in Uganda and physical or sexual violence in Zimbabwe. ${ }^{89}$ However, a third non-experimental study in Uganda found increases in 'indecent touching'. ${ }^{10}$ Despite some promising results, because these studies tested combined effects of MFI-plus programmes, they cannot determine the net contribution of MFI alone or synergistic effects of programme components. Thus, the existing evidence cannot conclude whether the bundled MFI-plus was necessary for the observed reductions in VAC or whether offering access to MFI-only services would have been sufficient.

Despite this limited evidence, the recommendation on MFIs could be justified if there was evidence of reduction in IPV or in children's witnessing of the same. However, this evidence is lacking, including from three rigorous randomised controlled trials (RCTs) the INSPIRE strategy relies on. In northern Cote d'Ivoire, a combined VSLA and gender dialogue intervention reported significantly reduced economic abuse among partnered women aged 18 years and older, compared with the savings only group. ${ }^{11}$ However, it had no significant effect on sexual or physical violence. Note that the INSPIRE document reports effects only for women who attend at least $75 \%$ of sessions (what the authors term the 'high adherence group'), who experience reductions in exposure to past-year physical IPV. However, these results come from a per protocol analysis, which cannot disentangle women's characteristics which motivate them to attend the programme (eg, the high adherers), from impacts. In Burundi, access to VSLAs plus eight couples' sessions focusing on conflict-resolution skills reports no significant overall effects, compared with VSLA access only. ${ }^{12}$ Finally, in rural South Africa, the Intervention with Microfinance for AIDS and Gender Equity (IMAGE) offering access to microloans paired with gender and life skill sessions and a community mobilisation component, reduced physical or sexual IPV in the last 12 months by $55 \%$ among clients in treated villages, compared with the age-matched random sample in control villages. ${ }^{13}$ Although the IMAGE results are promising, authors could not disentangle the effects of the MFI from the gender and lifeskill training. In addition, these estimates measure the effect of the intervention on clients (ie, the effect of the 'Treatment-on-the-Treated'), but do not tell us if IMAGE reduced exposure to IPV in the population of eligible women in treated villages (ie, the 'Intent-to-Treat' effect). This may be problematic for generalisability of findings, as women from the general population are likely to be different from women who take up MFI programmes.
Taken together, these studies do not test the hypothesis that MFIs alone result in reductions in IPV, nor do they provide evidence in support of a marginal effect of the 'plus' component, or of the synergistic effects between MFI and the 'plus' components. The only study to show an incremental synergistic effect of MFI-plus interventions (compared with access to MFI-only) on reduction in IPV exposure is Kim et als three-way comparison between IMAGE clients, MFI-only clients and age-matched controls. ${ }^{14}$ While encouraging, these findings, too, are likely to apply to women who decide to take up MFI and MFI-plus services when these are offered, who may be a low proportion of all adult women and may differ from the general population, along key characteristics associated with both risk factors and potential for impacts. ${ }^{15}$ For example, Karlan et al examine take-up rates among MFIs across 13 projects and find that rates are between $2 \%$ and $84 \%$ of eligible individuals. ${ }^{15}$ Finally, a recent RCT in Burkina Faso, published after the release of the INSPIRE guidelines, found that an economic intervention alone (including VLSA), as well as the economic intervention plus family coaching reduced emotional IPV (with no change for physical IPV). ${ }^{16}$ However, since the economic intervention also included livelihood training, seed capital grants and one-on-one mentoring, the study is unable to attribute impacts to the VSLA alone, versus other components.

Important to the discussion of disentangling impacts, it has been suggested that MFIs alone could increase risk of IPV and that added components are in fact needed to mitigate against adverse impacts. ${ }^{2}$ However, as Gibbs and colleagues show, these adverse IPV impacts have been found in associational studies only, and there is no evidence these relationships are causal. Moreover, a systematic review of group-based self-help programmes (including MFIs), finds no evidence that these programmes increase IPV. ${ }^{17}$ The claim that MFIs lead to increases in violence based on quantitative evidence appears to rely on misinterpretation of correlation as causality. While 'male backlash' is a theoretical possibility, there is little causal empirical evidence of this occurrence within women's economic empowerment programming. Despite this, it is important to continually monitor for and evaluate the potential for adverse impacts and there exists specific guidance of how to implement such efforts. $^{18}$

The question whether it is MFI-only or the synergistic effects of MFI-plus programming that drives reductions in violence also has implications for cost and scalability. For example, if the economic component alone is sufficient, but synergies with additional programmes deliver larger impacts, or more sustainable impacts, then the overall cost-effectiveness over medium and long term should determine optimal investments. In contrast, if the 'plus' component is driving impacts, then an appropriate recommendation would be to scale up, refine and distill key components of the same. When determining population-level investments, there is a trade-off between 
scaling-up leaner programmes to more beneficiaries and implementing more complex, costly programmes to fewer beneficiaries. It is possible that layered programmes will lead to greater cost-effectiveness. However, to our knowledge, no empirical study has investigated this trade-off. In addition, underlying gendered norms around women's economic empowerment may take time to change, and thus the current RCT-based evidence may underestimate impacts due to the short time frame for evaluation. However, this may not always be the case, and in addition to long-term experimental studies, well-designed, longterm cohort or quasi-experimental studies can contribute to addressing these questions. Finally, high-quality qualitative research can provide insights on context and challenges for recipients and implementers and on possible mechanisms of impact.

The weak evidence for MFIs reducing violence is of particular concern when viewed as part of the broader evidence on poverty and human capital impacts of MFIs. Prominent RCT-based studies and systematic reviews suggest that MFIs have failed to deliver on their primary poverty and revenue objectives, as well as on the specific objective of improving the financial standing of women. ${ }^{19} 20$ Some evidence suggests that MFIs can be beneficial for certain populations, namely, the entrepreneurially minded among the poor. ${ }^{19}$ However, the extreme poor who are liquidity constrained are often not able to pay back loans (particularly loans with high interest rates) and may not be well positioned to engage in small business activities. ${ }^{20}$ The conclusion that MFIs have inconsistent and often null impacts on economic outcomes, the main mediator through which they are hypothesised to impact violence, should encourage INSPIRE to reconsider their potential for violence reduction and further encourage studies that rigorously evaluate direct and synergistic impacts of MFI-plus packages.

With an estimated one billion children under age 18 suffering from emotional, physical or sexual violence every year, and one in three women experiencing IPV in their lifetime, the stakes are too high to make leaps of faith. ${ }^{21} 22$ The INSPIRE package indicates that recommended strategies are not meant to be comprehensive and rather can be seen as 'illustrative models' (pp 22). Despite this caveat, INSPIRE is currently being recommended as a model for implementation and strategic investment globally. ${ }^{23}$ Accordingly, we encourage global stakeholders to use the most up to date and comprehensive evidence available and to commission additional research where gaps exist. This research must be able to identify causality, be sufficiently powered to detect effects between economic strengthening and other components, tested in the long term, in multiple settings through scalable models and include cost-effectiveness estimates. There are many diverse typologies of economic strengthening interventions and policy levers, and we have only begun to scratch the surface to understand how they affect violence. There exists little conclusive empirical evidence that MFIs, either directly or synergistically with gender norms or equity training, can reduce VAC or IPV. We encourage the global stakeholders to 'look before they leap' and make investments in evidence generation around economic strengthening before scaling-up potentially ineffective interventions.

Contributors AP wrote the first draft of the manuscript. TP and GF critically reviewed and revised the manuscript. All authors conceptualised the manuscript, reviewed the literature and interpreted the evidence equally and approved the content. The viewpoints expressed here are those of the authors and do not necessarily represent the official positions of the affiliated institutions.

Disclaimer The views expressed in this article are those of the authors and not the policies or views of their affiliated institutions.

Competing interests None declared

Patient consent Not required.

Provenance and peer review Not commissioned; externally peer reviewed.

Data sharing statement No additional data are available.

Open access This is an open access article distributed in accordance with the Creative Commons Attribution Non Commercial (CC BY-NC 4.0) license, which permits others to distribute, remix, adapt, build upon this work non-commercially, and license their derivative works on different terms, provided the original work is properly cited, appropriate credit is given, any changes made indicated, and the use is non-commercial. See: http://creativecommons.org/licenses/by-nc/4.0/

\section{REFERENCES}

1. Buller AM, Peterman A, Ranganathan M, et al. A mixed-method review of cash transfers and intimate partner violence in low- and middle-income countries. World Bank Res Obs 2018;33:218-58.

2. Gibbs A, Jacobson J, Kerr Wilson A. A global comprehensive review of economic interventions to prevent intimate partner violence and HIV risk behaviours. Glob Health Action 2017;10(sup2):1290427.

3. Peterman A, Neijhoft AN, Cook S, et al. Understanding the linkages between social safety nets and childhood violence: a review of the evidence from low- and middle-income countries. Health Policy Plan 2017;32:1049-71.

4. Taylor G, Bell E, Jacobson J, 2015. Addressing violence against women and girls through DFID's economic development and women's economic eEmpowerment programmes. London: The Department for International Development. Available from: https:// assets.publishing.service.gov.uk/government/uploads/system/ uploads/attachment_data/file/444143/Economic-Development-PartA_2_.pdf;

5. World Health Organization. INSPIRE: seven strategies for ending violence against children. Geneva: WHO, 2016.

6. Meinck F, Cluver LD, Boyes ME, et al. Risk and protective factors for physical and sexual abuse of children and adolescents in Africa: a review and implications for practice. Trauma Violence Abuse 2015;16:81-107.

7. Abramsky T, Watts $\mathrm{CH}$, Garcia-Moreno C, et al. What factors are associated with recent intimate partner violence? Findings from the WHO multi-country study on women's health and domestic violence. BMC Public Health 2011;11:109.

8. Bandiera O, Buehren N, Burgess R, et al. Women's empowerment in action: evidence from a randomized control trial in Africa: World Bank; 2017.

9. Dunbar MS, Kang Dufour MS, Lambdin B, et al. The SHAZ! project: results from a pilot randomized trial of a structural intervention to prevent HIV among adolescent women in Zimbabwe. PLoS One 2014;9:e113621.

10. Austrian K, Muthengi E. Can economic assets increase girls' risk of sexual harassment? Evaluation results from a social, health and economic asset-building intervention for vulnerable adolescent girls in Uganda. Child Youth Serv Rev 2014;47:168-75.

11. Gupta J, Falb KL, Lehmann H, et al. Gender norms and economic empowerment intervention to reduce intimate partner violence against women in rural Côte d'Ivoire: a randomized controlled pilot study. BMC Int Health Hum Rights 2013;13:46.

12. lyengar R, Ferrari G. Discussion sessions coupled with microfinancing may enhance the role of women in household decision-making in Burundi. NBER working papers series. 2011, 2011. 
13. Pronyk PM, Hargreaves JR, Kim JC, et al. Effect of a structural intervention for the prevention of intimate-partner violence and HIV in rural South Africa: a cluster randomised trial. Lancet 2006;368:1973-83.

14. Kim J, Ferrari G, Abramsky T, et al. Assessing the incremental effects of combining economic and health interventions: the IMAGE study in South Africa. Bull World Health Organ 2009;87:824-32.

15. Karlan D, Morduch J, Mullainathan S. Take-up: why microfinance take-up rates are low \& why it matters. Financial Access Initiative Research Framing Note New York: Financial Access Initiative, 2010.

16. Ismayilova L, Karimli L, Gaveras E, et al. An integrated approach to increasing women's empowerment status and reducing domestic violence: results of a cluster-randomized controlled trial in a West African country. Psychol Violence 2017;8:448-59.

17. Brody $\mathrm{C}$, Hoop Tde, Vojtkova $\mathrm{M}$, et al. Can self-help group programs improve women's empowerment? A systematic review. J Dev Effect 2017;9:15-40.

18. Bloom S, Levy J, Karim N, et al. Guidance for gender based violence (GBV) monitoring and mitigation within non-GBV focused sectoral programming. Atlanta: CARE, 2014.
19. Banerjee A, Karlan D, Zinman J. Six randomized evaluations of microcredit: introduction and further steps. Am Econ J Appl Econ 2015;7:1-21.

20. Stewart R, Van Rooyen C, Korth M, et al. Do micro-credit, microsavings and micro-leasing serve as effective financial inclusion interventions enabling poor people, and especially women, to engage in meaningful economic opportunities in low- and middleincome countries?: a systematic review of the evidence. London: EPPI-Centre, Social Science Research Unit, Institute of Education, University of London, 2012.

21. Devries KM, Mak JY, García-Moreno C, et al. Global health. The global prevalence of intimate partner violence against women. Science 2013;340:1527-8.

22. Hillis S, Mercy J, Amobi A, et al. Global prevalence of past-year violence against children: a systematic review and minimum estimates. Pediatrics 2016;137:e20154079.

23. World Health Organization. INSPIRE handbook: action for implementing the seven strategies for ending violence against children. Geneva: World Health Organization, 2018. 